\title{
Impact of MTHFR polymorphisms on methylation of MGMT in glioma patients from Northeast China with different folate levels
}

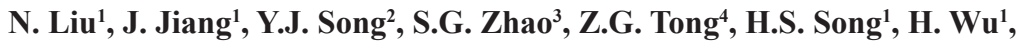
J.Y. Zhu' ${ }^{1}$, Y.H. Gu ${ }^{1}$, Y. Sun ${ }^{1}$, W. Hua ${ }^{1}$ and J.P. Qi ${ }^{1}$

'Department of Pathology, First Affiliated Hospital of Harbin Medical University, Nangang District, Harbin, China

${ }^{2}$ Department of Digestive System,

First Affiliated Hospital of Harbin Medical University, Harbin, China

${ }^{3}$ Department of Neurosurgery,

First Affiliated Hospital of Harbin Medical University, Harbin, China

${ }^{4}$ Department of Surgical Oncology,

Fourth Affiliated Hospital of Harbin Medical University,

Nangang District, Harbin, China

Corresponding author: J.P. Qi

E-mail: jipingqi@yeah.net

Genet. Mol. Res. 12 (4): 5160-5171 (2013)

Received March 26, 2013

Accepted August 19, 2013

Published October 29, 2013

DOI http://dx.doi.org/10.4238/2013.October.29.10

\begin{abstract}
Hypomethylation of the O6-methylguanine-DNAmethyltransferase (MGMT) promoter in glioma cells has been associated with temozolomide resistance. S-adenosylmethionine (SAM), which is produced during folate metabolism, is the main source of methyl groups during DNA methylation. As a key enzyme during folate metabolism, polymorphisms of 5,10-methylenetetrahydrofolate reductase (MTHFR) may regulate folate end-products. We investigated the effect of typical polymorphisms of MTHFR (C677T and A1298C) on MGMT methylation based on different serum folate levels in patients with glioma from Northeast China. A total of 275 patients with glioma and 329 without malignant
\end{abstract}


tumors were tested. Serum folate concentration was assayed by using the electrochemiluminescence immunoassay. MTHFR polymorphisms were detected by Taqman-Fluorescence quantitative polymerase chain reaction (PCR). Methylation-specific PCR was used to assess MGMT methylation. The constituent ratio of glioma patients below the serum folate biological reference value was significantly higher than that of the control population $(\mathrm{P}<0.001)$. In patients with oligodendroglioma and glioblastoma, heterozygotes for the A1298C mutation were found in higher frequency than homozygotes or wild types (oligodendroglioma, $\mathrm{P}<0.001$; glioblastoma, $\mathrm{P}<0.01)$. When grouped by the median or biological reference value of serum folate, only homozygotes for C677T with low levels of folate were significantly associated with decreased methylation of MGMT (median, $\mathrm{P}$ $<0.001$; biological reference value, $\mathrm{P}=0.036$ ). These data suggest that, in combination with a negative folate balance in glioma patients, $\mathrm{T} / \mathrm{T}$ genotypes in MTHFR C677T may be associated with MGMT demethylation.

Key words: Glioma; MGMT; MTHFR; Polymorphisms; Folate

\section{INTRODUCTION}

Glioma is the most common primary tumor in the central nervous system. It has poor prognosis owing to its characteristics of infiltrative growth, has no clear boundary with normal brain tissues, and has a poor response rate to surgery. There is a common perception that chemotherapy is an important part of the comprehensive therapy of glioma. In recent years, temozolomide (TMZ) has become a regular antitumor drug owing to its low incidence of side effects, but it can only be used in some patients due to drug resistance. Many researchers have studied the causes of TMZ resistance, and the involvement of O6-methylguanine-DNAmethyltransferase (MGMT) has been suggested.

MGMT is a cellular enzyme that directly repairs DNA damage and rapidly reverses alkylation at the $\mathrm{O} 6$ position of guanine to its cysteine residues. Furthermore, MGMT becomes irreversibly inactivated after transmethylation (Dehan et al., 2009). Therefore, this repair mechanism is a double-edged sword as it is also the main reason for resistance of malignant glioma cells against carmustine and TMZ (Lee et al., 2011; Tawbi et al., 2011).

MGMT often becomes deactivated due to methylation, and DNA methylation is an important part of the post-DNA synthesis modification process. Normally, methylation is catalyzed by DNA methyltransferase, and the cytosines of $\mathrm{CpG}$ islands in DNA are selectively added with methyl chemical modification. Transformation of DNA methylation can lead to abnormalities in genetic structure, which causes abnormalities in gene expression and instability of the whole genome, or even tumor formation (El-Osta, 2003; Kondo et al., 2003; Roll et al., 2008; Zhang and Chen, 2010). There are many factors that influence DNA methylation, such as methyltransferases (Tamaru and Selker, 2001; Nandan et al., 2008), histone methylation (Bae et al., 2002; Long et al., 2010), and dietary factors.

Folate is an essential vitamin and 5,10-methylenetetrahydrofolate reductase (MTHFR) is a key enzyme during its metabolism (Figure 1). The MTHFR gene is located in chromosome $1 \mathrm{p} 36.3$, and folate eventually produces S-adenosylmethionine (SAM). SAM is produced dur- 
ing the metabolism of folate and is the main source of methyl groups during DNA methylation. MTHFR gene polymorphisms usually result in protein changes. If cytosine changes to thymine at site 677 of the MTHFR gene (C677T), alanine is replaced by valine. If adenine changes to cytosine at site 1298 (A1298C), glutamate is replaced by adenine (Schaich et al., 2009). Polymorphisms of MTHFR often reduce its enzymatic activity, which affects the production of SAM as well as the level of methylation of the whole genome (including DNA repair genes).

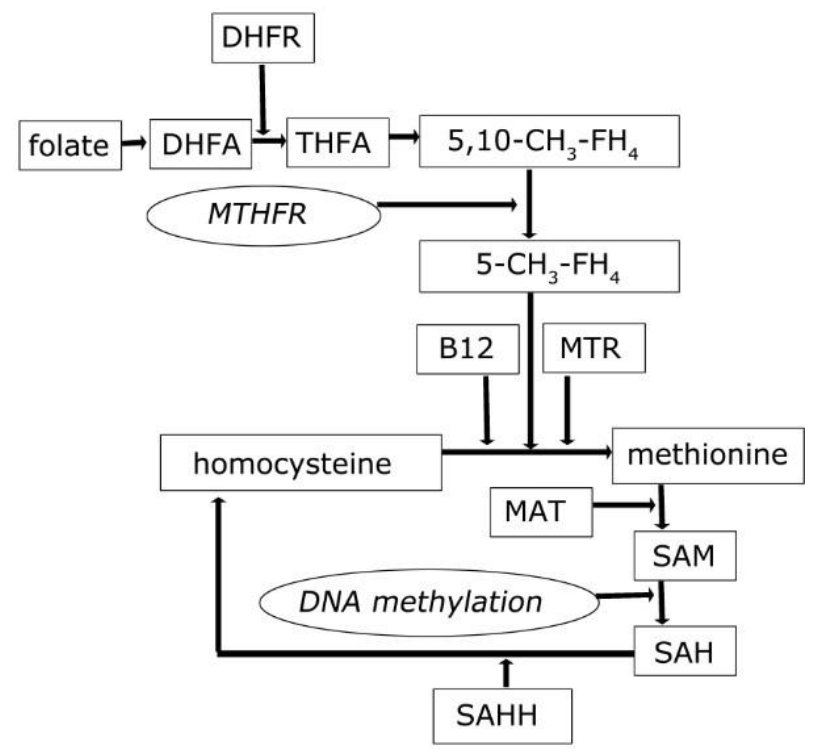

Figure 1. Human folate metabolism. First, folate becomes dihydrofolic acid (DHFA), which is then catalyzed to tetrahydrofolic acid (THFA) by dihydrofolic acid reductase (DHFR). THFA is then converted to 5,10-methyltetrahydrofolic acid $\left(5,10-\mathrm{CH}_{3}-\mathrm{FH}_{4}\right)$ and the latter becomes 5-methyltetrahydrofolic acid $\left(5-\mathrm{CH}_{3}-\right.$ $\mathrm{FH}_{4}$ ), which is catalyzed by FAD-dependent MTHFR. In another transversion, homocysteine is remethylated to methionine, assisted by cofactors, which contain $5-\mathrm{CH}_{3}-\mathrm{FH}_{4}$, a derivate of vitamin $\mathrm{B} 12$, and methionine synthase (MTR). Methionine is converted to SAM, which is used for DNA methylation, and the degradation product of SAM is S-adenosylhomocysteine ( $\mathrm{SAH}$ ). SAH is catalyzed by homocysteine hydrolase (SAHH) to homocysteine, which becomes methionine again, thus forming a reaction cycle.

The present study investigated the effects of interactions between MTHFR C677T or A1298C mutations and folate levels on MGMT methylation, and aimed to provide a more theoretical and experimental basis for analyzing glioma.

\section{MATERIAL AND METHODS}

\section{Patients}

This study was approved by the Ethics Committee of the Medical Faculty of Harbin Medical University in accordance with the Declaration of Helsinki. Peripheral venous blood was taken after overnight fasting from ethnic Han Chinese patients who were pathologically diagnosed with glioma after neurosurgery in the First, Second, and Fourth Affiliated Hospitals 
of Harbin Medical University from December 2009 to January 2011. Two hundred seventyfive patients (149 male and 126 female; mean age $47 \pm 9.43$ years) were enrolled in the study. Patients who had undergone previous chemotherapy or radiotherapy were not included. All histopathological diagnoses were made at the three hospitals in accordance with the 2007 WHO Classification of Tumors of the Central Nervous System. There were 106 astrocytomas, 91 oligodondrogliomas, and 62 glioblastomas. The control group comprised 329 patients who had undergone physical examinations (154 male and 170 female; mean age $46 \pm 11.03$ years), were also ethnic Han Chinese, and had no tumor family history.

\section{Serum folate concentration assay}

Serum folate was measured with an electrochemiluminescence immunoassay, using an Elecsys Folate Kit and an Elecsys2010 immunoassay analyzer (Roche, Germany). The coefficient of variation for the assays was less than $5 \%$. For each sample, the immunoassay analyzer automatically calculated the folate concentration. The reference value for serum folate in the general population in Northeast China is $2.34-17.56 \mathrm{ng} / \mathrm{mL}$.

\section{DNA extraction and MTHFR C677T and A1298C polymorphisms}

Aqua-spin blood gDNA isolation mini kits (Watson Biotechnologies, Shanghai, China) were used for DNA extraction. We analyzed the concentration, purity, and completeness of the extracted DNA by spectrophotometry and gel electrophoresis. The genetic polymorphisms of MTHFR were typed by Taqman-Fluorescence quantitative polymerase chain reaction (PCR). All primers and TaqMan probes were designed by our laboratory and synthesized by GeneCore Bio Technologies (Shanghai, China): C677T forward: 5'-CTTCACAAAGCGGAAGAATGTGT-3', reverse: 5'-GACCTGAAGCACTTGAAGG AGAA-3'; TaqMan probe 1: 5'-FAM-TGATGAAAT CGGCTCCGCAG-BHQ-3', TaqMan probe 2: 5'-HEX-TGATGAAATCGACTCCCGCAGACABHQ-3'; A1298C forward: 5'-GGTTTGGTTCTCCCGAGAGG-3', reverse: 5'-GCAAGTCCCC CAAGGAGG-3'; TaqMan probe 1: 5'-FAM-AAGACACTTTCTTCACTG-MGB-3', TaqMan probe 2: 5'-HEX-AGACACTTGCTTCACT-MGB-3'. PCR was performed as previously described (Kaur et al., 2011).

\section{Methylation-specific PCR}

EZ DNA Methylation-Gold ${ }^{\mathrm{TM}}$ kits (Zymo Research, Irvine, CA, USA) were used for bisulfite modification according to manufacturer instructions. The MGMT methylated forward primer was 5'-TTTCGACGTTCGTAGGTTTTCGC-3' and the reverse primer was 5'-GCAC TCTTCCGAAAACGAAA CG-3'. The unmethylated forward primer was 5'-TTTGTGTTTTG ATGTTTGTAGGTTTTT GT-3' and the reverse primer was 5'-AACTCCACACTCTTCCAAA AACAAAACA-3' (Shah et al., 2011). PCR conditions were $95^{\circ} \mathrm{C}$ for $2 \mathrm{~min}$, followed by 40 cycles of $95^{\circ} \mathrm{C}$ for $15 \mathrm{~s}, 66^{\circ} \mathrm{C}$ for $15 \mathrm{~s}$, and $72^{\circ} \mathrm{C}$ for $15 \mathrm{~s}$, and a 7 min extension at $72^{\circ} \mathrm{C}$.

\section{Statistical analysis}

Quantitative data are described as median and interquartile range. A rank sum 
test was performed to compare the quantitative data between the two groups, which is shown as the rate or constituent ratio. The $\chi^{2}$ test was adopted for comparisons among groups. The $\chi^{2}$ segmentation method was used for multiple comparisons. Fisher's exact test was performed where sample sizes were small. A goodness-of-fit test was conducted with regard to the frequency distribution within a single group. All of the above tests were performed with SPSS version 12.0 with the significance level uniformly defined at $\mathrm{P}<0.05$.

\section{RESULTS}

\section{Serum folate determination}

Table 1 shows the results of serum folate concentration comparisons between glioma patients and the normal control population. Patients who had a serum folate level $<2.34 \mathrm{ng} / \mathrm{mL}$ comprised $22.5 \%$ of the total, which was significantly higher than that of the general population at only $5.2 \%(\mathrm{P}<0.05)$.

Table 1. Analysis of serum folate concentration in glioma and control group.

\begin{tabular}{lccc}
\hline & Median $(\mathrm{P} 25-\mathrm{P} 75)(\mathrm{ng} / \mathrm{mL})$ & $<2.34 \mathrm{ng} / \mathrm{mL}(\mathrm{N}, \%)$ & $2.34-17.56 \mathrm{ng} / \mathrm{mL}(\mathrm{N}, \%)$ \\
\hline Glioma $(\mathrm{N}=275)$ & $9.44(2.97-15.32)$ & $62(22.5)$ & $213(77.5)$ \\
Control group $(\mathrm{N}=329)$ & $12.48(4.78-15.99)$ & $17(5.2)$ & $312(94.8)$ \\
P value & $<0.05^{*}$ & & $<0.0001^{\#}$ \\
\hline
\end{tabular}

Serum folate levels of glioma and control groups are presented as median (interquartile range). *Using Wilcoxon rank sum test for comparison of the folate distribution difference, the threshold with $\alpha=0.05$. "Using $\chi^{2}$ test fourfold table.

\section{Characteristics of the experimental groups and analysis of MTHFR genotypes}

Figure 2 shows the genotypes identified by Taqman-Fluorescence quantitative PCR. We analyzed 273 of the 275 genotypes from glioma samples and 326 of the 329 genotypes in the control group. To establish whether the control group was representative of the general population, we conducted a Hardy-Weinberg equilibrium test on MTHFR genotypes using the $\chi^{2}$ test. Table 2 shows the distribution of the expected and actual values of MTHFR C677T, which did not differ significantly $(\mathrm{P}>0.05)$, indicating that the samples were in genetic equilibrium, and those of the control group were representative of the general population. Similar results were obtained for MTHFR A1298C (P > 0.05). With regard to the association between MTHFR polymorphisms and risk of glioma, we found that the three genotypes for C677T were not correlated with risk of glioma ( $\mathrm{P}>$ 0.05 ; odds ratio $(\mathrm{OR})<1)$. For $\mathrm{A} 1298 \mathrm{C}$, the heterozygotes $(\mathrm{A} / \mathrm{C})$ showed an increased risk of glioma compared with the wild type genotypes $(\mathrm{P}<0.05$; OR $=1.447$; $95 \%$ confidence interval (CI), 1.012-2.069). Moreover, we found significant differences between each genotype for A1298C and histological classifications of glioma $(\mathrm{P}<0.001)$, but we did not find any correlations with MGMT methylation. We failed to find any other features related to MTHFR polymorphisms. In multiple comparisons between different types of glioma, we found that the heterozygotes for A1298C occurred most frequently 
in oligodendroglioma $(64.8 \%)$ and glioblastoma $(53.9 \%)(\mathrm{P}<0.01)$. The above results are shown in Tables 3-5.

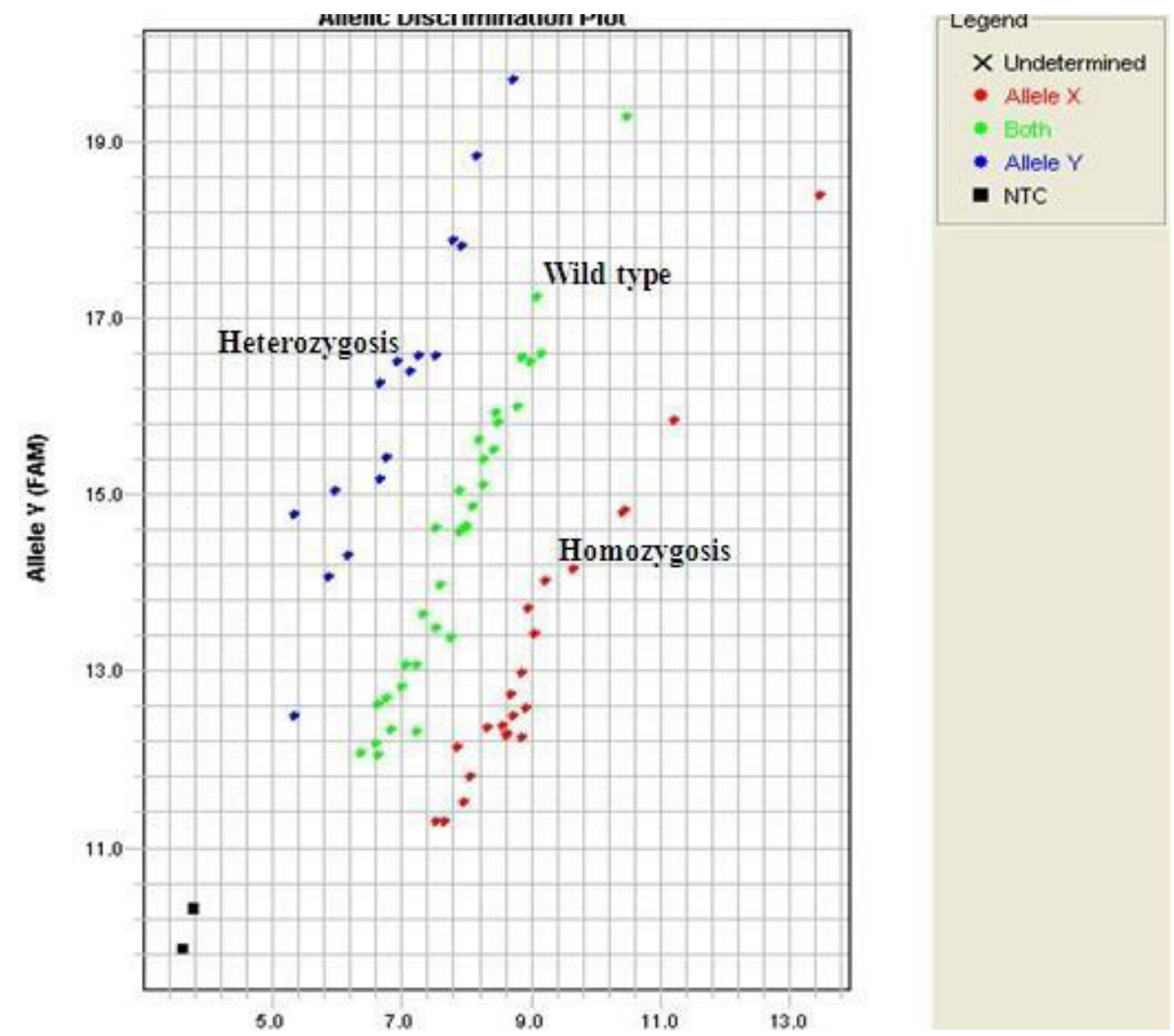

Figure 2. Genotypes defined by Taqman-fluorescence quantitative PCR. Abscissa = signal strength of HEX; Ordinate $=$ signal strength of FAM; allele X (red dots) $=$ homozygosis; both (green dots) = heterozygosis; Y (blue dots $)=$ wild type; NTC (black dots) $=$ no template control.

Table 2. Hardy-Weinberg equilibrium (HWE) for MTHFR polymorphisms in control group.

\begin{tabular}{lrrr}
\hline Genotypes & Actual value (\%) & Expected value (\%) & HWE \\
\hline C677T & & & \\
C/C & $63(19.3)$ & $61.4(18.8)$ & NS \\
T/T & $106(32.5)$ & $104.4(32.0)$ & \\
C/T & $157(48.2)$ & $160.1(49.1)$ & \\
A1298C & $137(42.0)$ & $125.7(38.5)$ & NS \\
A/A & $58(17.8)$ & $46.8(14.4)$ & $153.5(47.1)$ \\
C/C & $131(40.2)$ & A/C & \\
\hline
\end{tabular}

HWE exact test $\mathrm{P}$ value; $\mathrm{NS}=$ not significant. Single nucleotide polymorphism frequencies were tested for departure from HWE using $\chi^{2}$ test. 
Table 3. Risk of glioma associated with MTHFR polymorphisms.

\begin{tabular}{lrrcl}
\hline & Glioma (N, \%) & Control (N, \%) & P value & OR (95\%CI) \\
\hline C677T & & & & \\
C/C & $60(21.9)$ & $63(19.3)$ & - & 1.000 (reference) \\
T/T & $87(31.9)$ & $106(32.5)$ & N.S. & $0.862(0.548-1.356)$ \\
C/T & $126(46.2)$ & $157(48.2)$ & N.S. & $0.843(0.551-1.288)$ \\
A1298C & $94(34.4)$ & $137(42.0)$ & - & 1.000 (reference) \\
A/A & $44(16.1)$ & $58(17.8)$ & N.S. & $0.981(0.615-1.565)$ \\
C/C & $135(49.5)$ & $131(40.2)$ & $0.042^{*}$ & $1.447(1.012-2.069)$ \\
A/C
\end{tabular}

$\overline{\mathrm{OR}}=$ odds ratio $; 95 \% \mathrm{CI}=95 \%$ confidence interval; N.S. $=$ not significant. Main outcome measures: risk factors for glioma were studied by unconditioned logistic regression analysis. $* \mathrm{P}<0.05$.

Table 4. Characteristics of the population according to MTHFR polymorphisms at C677T.

\begin{tabular}{|c|c|c|c|c|}
\hline & $\mathrm{C} / \mathrm{C}(\mathrm{N}, \%)$ & $\mathrm{T} / \mathrm{T}(\mathrm{N}, \%)$ & $\mathrm{C} / \mathrm{T}(\mathrm{N}, \%)$ & $\mathrm{P}$ value \\
\hline \multicolumn{5}{|l|}{ Age $(\mathrm{N}=599)$} \\
\hline$\geq 50(\mathrm{~N}=291)$ & $58(19.9)$ & $98(33.7)$ & $135(46.4)$ & \\
\hline$<50(\mathrm{~N}=308)$ & $65(21.1)$ & $95(30.8)$ & $148(48.1)$ & NS \\
\hline \multicolumn{5}{|l|}{ Gender $(\mathrm{N}=599)$} \\
\hline Male $(\mathrm{N}=303)$ & $68(22.4)$ & $90(29.7)$ & $145(47.9)$ & \\
\hline Female $(\mathrm{N}=296)$ & $55(18.6)$ & $103(34.8)$ & $138(46.6)$ & NS \\
\hline \multicolumn{5}{|l|}{ Histology $(\mathrm{N}=273)$} \\
\hline Astrocytoma $(\mathrm{N}=106)$ & $22(20.8)$ & $28(26.4)$ & $56(52.8)$ & \\
\hline Oligodendroglioma $(\mathrm{N}=91)$ & $20(22.0)$ & $27(29.7)$ & $44(48.4)$ & \\
\hline Glioblastoma $(\mathrm{N}=76)$ & $18(24.7)$ & $32(42.1)$ & $26(35.6)$ & NS \\
\hline
\end{tabular}

$\mathrm{NS}=$ not significant. Statistical difference was evaluated by $\chi^{2}$ test.

Table 5. Characteristics of the population according to MTHFR polymorphisms at A1298C.

\begin{tabular}{|c|c|c|c|c|}
\hline & $\mathrm{A} / \mathrm{A}(\mathrm{N}, \%)$ & $\mathrm{C} / \mathrm{C}(\mathrm{N}, \%)$ & $\mathrm{A} / \mathrm{C}(\mathrm{N}, \%)$ & P value \\
\hline \multicolumn{5}{|l|}{ Age $(\mathrm{N}=599)$} \\
\hline$\geq 50(\mathrm{~N}=291)$ & $105(36.1)$ & $50(17.2)$ & $136(46.7)$ & \\
\hline$<50(\mathrm{~N}=308)$ & $126(40.9)$ & $52(16.9)$ & $130(42.2)$ & NS \\
\hline \multicolumn{5}{|l|}{ Gender $(\mathrm{N}=599)$} \\
\hline Male $(\mathrm{N}=303)$ & $123(40.6)$ & $49(16.2)$ & $131(43.2)$ & \\
\hline Female $(\mathrm{N}=296)$ & $108(36.5)$ & $53(17.9)$ & $135(45.6)$ & NS \\
\hline \multicolumn{5}{|l|}{ Histology $(\mathrm{N}=273)$} \\
\hline Astrocytoma $(\mathrm{N}=106)$ & $45(42.5)^{* *}$ & $30(28.3)^{* \#}$ & $31(29.2)^{* \#}$ & \\
\hline Oligodendroglioma $(\mathrm{N}=91)$ & $28(30.8)^{* \dagger}$ & $4(4.4)^{* \dagger}$ & $59(64.8)^{* \dagger}$ & \\
\hline Glioblastoma $(\mathrm{N}=76)$ & $25(32.9)^{\not \dagger}$ & $10(13.2)^{\# \dagger}$ & $41(53.9)^{\# \dagger}$ & $<0.0001$ \\
\hline
\end{tabular}

$\mathrm{NS}=$ not significant. $\chi^{2}$ segmentation method was used for multiple comparisons concerning the risk between single nucleotide polymorphism and histology. *Astrocytoma compared with oligodendroglioma: $\chi^{2}=31.593, \mathrm{P}$ $<0.0001 .{ }^{*}$ Astrocytoma compared with glioblastoma: $\chi^{2}=12.498, \mathrm{P}=0.002$. ${ }^{\dagger}$ Oligodendroglioma compared with glioblastoma: $\chi^{2}=4.672, \mathrm{P}=0.097$

\section{Correlation between promoter methylation of MGMT and MTHFR polymorphisms in glioma patients with different levels of serum folate}

The methylation incidence of MGMT in glioma was $41.8 \%$, which was significantly higher than that in the control group $(\mathrm{P}<0.0001)$. Among patients with serum folate levels below the median value of $9.44 \mathrm{ng} / \mathrm{mL}$, homozygotes for C677T were found at a lower frequency than the other genotypes $(\mathrm{P}=0.001)$. However, in patients with serum folate levels $>9.44 \mathrm{ng} /$ 
$\mathrm{mL}$, the opposite phenomenon was observed. With respect to A1298C, although homozygotes were also found at the lowest frequency when serum folate levels were below the median value, this effect was not statistically significant $(\mathrm{P}>0.05)$ (Table 6).

\begin{tabular}{|c|c|c|c|c|c|c|c|c|}
\hline & $\mathrm{N}$ & $\mathrm{SF} \geq 9.44 \mathrm{ng} / \mathrm{mL}(\mathrm{N}, \%)$ & $\mathrm{SF}<9.44 \mathrm{ng} / \mathrm{mL}(\mathrm{N}, \%)$ & $P$ value & $\mathrm{N}$ & $\mathrm{SF}<2.34 \mathrm{ng} / \mathrm{mL}(\mathrm{N}, \%)$ & $\mathrm{SF} 2.34-17.56 \mathrm{ng} / \mathrm{mL}(\mathrm{N}, \%)$ & $P$ value \\
\hline \multicolumn{9}{|l|}{ C677T } \\
\hline $\mathrm{C} / \mathrm{C}$ & 37 & $4(10.8)$ & $33(89.2)$ & - & 37 & $12(32.4)$ & $25(67.6)$ & - \\
\hline $\mathrm{T} / \mathrm{T}$ & 28 & $13(46.4)$ & $15(53.6)$ & $0.001^{*}$ & 28 & $2(7.1)$ & $26(92.9)$ & $0.014^{s}$ \\
\hline $\mathrm{C} / \mathrm{T}$ & 50 & $6(12.0)$ & $44(88.0)$ & $\mathrm{NS}^{*}$ & 50 & $14(28.0)$ & $36(72.0)$ & NS" \\
\hline \multicolumn{9}{|c|}{ A1298C } \\
\hline $\mathrm{A} / \mathrm{A}$ & 38 & $8(21.1)$ & $30(78.9)$ & - & 38 & $8(21.1)$ & $30(78.9)$ & - \\
\hline $\mathrm{C} / \mathrm{C}$ & 21 & $5(23.8)$ & $16(76.2)$ & $\mathrm{NS}^{+}$ & 21 & $6(28.6)$ & $15(71.4)$ & $\mathrm{NS}^{\mathrm{k}}$ \\
\hline $\mathrm{A} / \mathrm{C}$ & 56 & $10(17.9)$ & $46(82.1)$ & $\mathrm{NS}^{\star}$ & 56 & $14(25.0)$ & $42(75.0)$ & $\mathrm{NS}^{\varepsilon}$ \\
\hline
\end{tabular}

In practice, biological reference values are used to determine the levels of serum folate; therefore, our study population was divided into two groups according to the reference value. As indicated in Table 6, when serum folate was $<2.34 \mathrm{ng} / \mathrm{mL}$, homozygotes for C677T in glioma patients with MGMT methylation comprised a lower proportion than those with other genotypes $(\mathrm{P}=0.014)$. Moreover, statistical analysis showed no correlations between each A1298C genotype with MGMT methylation (P > 0.05).

\section{DISCUSSION}

Cells can repair DNA damage caused by external and internal mutagens, introduction of non-standard bases during replication, and disorders of DNA structure and sequence that result from mismatching bases. These repairs are carried out by the DNA repair enzyme system, which guarantees the normal transmission of genetic information. When the genes of these enzymes are mutated, the repair process can be adversely affected, which may lead to irreparable mutations in the genome, cause cancer, and determine tumor characteristics (Margison and Santibanez-Koref, 2002; Wood et al., 2005; Yoshino et al., 2010; Theocharis et al., 2011). Glioma is the most frequent type of primary brain tumor. In recent years, researchers have investigated MGMT and have observed that the occurrence of methylation in the gene for this enzyme is closely related to the carcinogenesis, development, and treatment of glioma (Esteller et al., 2000; Hegi et al., 2005).

Many previous studies have suggested that promoter methylation is the most common abnormity of MGMT (Virmani et al., 2001; Fang et al., 2005; Kim et al., 2009; Steinmann et al., 2009). With respect to the effects of MGMT on glioma, Uno et al. (2011) found that the positive rate of MGMT methylation was $43.1 \%$, and that methylation was related to low gene expression. Esteller et al. (2000) indicated that $40 \%$ of patients experienced MGMT promoter methylation, and higher levels of methylation were associated with a worse prognosis. An Asian survey demonstrated that, on average, $69 \%$ of glioma patients had methylated MGMT 
promoters, and the methylated population with low-grade tumors outnumbered that with highgrade tumors (Jha et al., 2010). In our study, $41.8 \%$ of glioma patients showed MGMT promoter methylation, which was clearly higher than that in the control group. These results support the conclusion that MGMT methylation plays an important role in the occurrence and development of glioma. MGMT promoter methylation results in gene silencing (Hegi et al., 2005; Uno et al., 2011), and is therefore considered a predictive factor for evaluating the effect of treatment by TMZ in glioblastoma multiforme (GBM) patients (Hegi et al., 2005).

The present study showed that the level of 5-methylcytosine in blood mononuclear cells was closely related to folate levels, and that this relationship was mediated by SAM. MTHFR catalyzes the conversion of 5,10-methylenetetrahydrofolate to 5-methyletrahydrofolate, which is required for SAM (Figure 1) (Kono and Chen, 2005). MTHFR C677T and A1298C polymorphisms increase thermal instability and reduce the activity of the enzymes, thus influencing the stability of DNA methylation and nucleic acids (Stern et al., 2000).

In the present study, serum folate was accepted as an indicator of the nutrient (Herbert, 1987; Bailey, 1990), and might serve as a reliable an indicator of its status in the blood as erythrocyte level (Friso et al., 2002). The levels of serum vitamins B12 and B6 were not evaluated here because Friso et al. (2002) demonstrated that they have nothing to do with one carbon unit. Our results indicated that the levels of folate in glioma patients were lower than those in the control group. This means that: i) insufficiency of folate may result in the development of tumors through some mechanism, such as affecting the methylation of nucleic acids (Wainfan and Poirier, 1992; Jacob et al., 1998), destroying DNA integrity (Blount et al., 1997), or influencing DNA repair (Kim et al., 1997; Choi et al., 1998), and ii) tumors induce other factors that can affect the level of serum folic acid.

With respect to the relationship between polymorphisms and protein activity of MTHFR, previous studies have found that homozygotes and wild type genotypes for both C677T and A1298C lead to changes in protein activity (Frosst et al., 1995; Bethke et al., 2008). Our results demonstrated that only patients who were heterozygous for C677T showed the highest rates of MGMT methylation, whereas those who were heterozygous for A1298C did not. However, are such changes associated with the risk of glioma? Our results showed that wild type genotypes, and those homozygous and heterozygous for C677T had no significant associations with the risk of glioma. For A1298C, only heterozygous genes were associated with the risk of glioma. Although single nucleotide polymorphisms have regional differences, our findings are nonetheless consistent with Bethke et al. (2008). Only a few studies have investigated polymorphisms of MTHFR in brain tumors to date. Kafadar et al. (2006) studied a small group of 74 patients, and their results generally coincided well with our own; they suggested that the MTHFR 677TT genotype was not associated with individual susceptibility. Linnebank et al. (2008) investigated 214 patients with GBM. Although they did not directly evaluate the association between MTHFR polymorphisms and GBM risk, their data suggested that the MTHFR C677T variant was a risk factor for survival in GBM patients. Bethke et al. (2008) investigated A1298C alone, and they suggested that heterozygotes were related to histological characteristics.

As mentioned above, the level of DNA methylation is associated with the serum folate level. C677T homozygotes were associated with demethylation, which otherwise appears only when there are low levels of folate (Friso et al., 2002; Pufulete et al., 2003; Kafadar et al., 2006). The mechanism for the occurrence of this phenomenon has been investigated. 
One possibility is that the $\mathrm{C} 677 \mathrm{~T}$ mutation results in exposure of binding sites for the flavin adenine dinucleotide (FAD) cofactor, which otherwise would be embedded in a barrel-like structure (Guenther et al., 1999). However, no information is currently available with regards to A1298C, and the results showed no relationship of this polymorphism to glioma. Establishing a clear association between MTHFR polymorphisms in glioma patients with different serum folate levels and MGMT promoter methylation will provide more genetic information for rational chemotherapy. In summary, when the levels of serum folate in glioma patients were low, homozygotes for the MTHFR C677T mutation were associated with MGMT demethylation, and possibly also with resistance against alkylating agents. Therefore, resistance to chemotherapeutic drugs, such as TMZ, might be measured based on the serum level of folate and polymorphisms for MTHFR C677T in glioma patients.

This study did not evaluate the mechanism of resistance or drug sensitivity test, which are currently underway in our lab. These results might provide more accurate measurement indicators for the clinical application of chemotherapeutic drugs.

\section{ACKNOWLEDGEMNTS}

Research supported by grant from the Scientific and Technological project of Heilongjiang Province, China (\#GC12C303-5).

\section{REFERENCES}

Bae SI, Lee HS, Kim SH and Kim WH (2002). Inactivation of O6-methylguanine-DNA methyltransferase by promoter CpG island hypermethylation in gastric cancers. Br. J. Cancer 86: 1888-1892.

Bailey LB (1990). Folate status assessment. J. Nutr. 120 (Suppl 11): 1508-1511.

Bethke L, Webb E, Murray A, Schoemaker M, et al. (2008). Functional polymorphisms in folate metabolism genes influence the risk of meningioma and glioma. Cancer Epidemiol. Biomark. Prev. 17: 1195-1202.

Blount BC, Mack MM, Wehr CM, MacGregor JT, et al. (1997). Folate deficiency causes uracil misincorporation into human DNA and chromosome breakage: implications for cancer and neuronal damage. Proc. Natl. Acad. Sci. U. S. A. 94: 3290-3295.

Choi SW, Kim YI, Weitzel JN and Mason JB (1998). Folate depletion impairs DNA excision repair in the colon of the rat. Gut 43: 93-99.

Dehan P, Kustermans G, Guenin S, Horion J, et al. (2009). DNA methylation and cancer diagnosis: new methods and applications. Expert. Rev. Mol. Diagn. 9: 651-657.

El-Osta A (2003). DNMT cooperativity--the developing links between methylation, chromatin structure and cancer. Bioessays 25: 1071-1084.

Esteller M, Garcia-Foncillas J, Andion E, Goodman SN, et al. (2000). Inactivation of the DNA-repair gene MGMT and the clinical response of gliomas to alkylating agents. N. Engl. J. Med. 343: 1350-1354.

Fang MZ, Jin Z, Wang Y, Liao J, et al. (2005). Promoter hypermethylation and inactivation of O(6)-methylguanine-DNA methyltransferase in esophageal squamous cell carcinomas and its reactivation in cell lines. Int. J. Oncol. 26: 615622.

Friso S, Choi SW, Girelli D, Mason JB, et al. (2002). A common mutation in the 5,10-methylenetetrahydrofolate reductase gene affects genomic DNA methylation through an interaction with folate status. Proc. Natl. Acad. Sci. U. S. A. 99: 5606-5611.

Frosst P, Blom HJ, Milos R, Goyette P, et al. (1995). A candidate genetic risk factor for vascular disease: a common mutation in methylenetetrahydrofolate reductase. Nat. Genet. 10: 111-113.

Guenther BD, Sheppard CA, Tran P, Rozen R, et al. (1999). The structure and properties of methylenetetrahydrofolate reductase from Escherichia coli suggest how folate ameliorates human hyperhomocysteinemia. Nat. Struct. Biol. 6: 359-365.

Hegi ME, Diserens AC, Gorlia T, Hamou MF, et al. (2005). MGMT gene silencing and benefit from temozolomide in glioblastoma. N. Engl. J. Med. 352: 997-1003. 
Herbert V (1987). Making sense of laboratory tests of folate status: folate requirements to sustain normality. Am. $J$. Hematol. 26: 199-207.

Jacob RA, Gretz DM, Taylor PC, James SJ, et al. (1998). Moderate folate depletion increases plasma homocysteine and decreases lymphocyte DNA methylation in postmenopausal women. J. Nutr. 128: 1204-1212.

Jha P, Suri V, Jain A, Sharma MC, et al. (2010). O6-methylguanine DNA methyltransferase gene promoter methylation status in gliomas and its correlation with other molecular alterations: first Indian report with review of challenges for use in customized treatment. Neurosurgery 67: 1681-1691.

Kafadar AM, Yilmaz H, Kafadar D, Ergen A, et al. (2006). C677T gene polymorphism of methylenetetrahydrofolate reductase (MTHFR) in meningiomas and high-grade gliomas. Anticancer Res. 26: 2445-2449.

Kaur G, Masoud A, Raihan N, Radzi M, et al. (2011). Mismatch repair genes expression defects \& association with clinicopathological characteristics in colorectal carcinoma. Indian J. Med. Res. 134: 186-192.

Kim JI, Suh JT, Choi KU, Kang HJ, et al. (2009). Inactivation of O6-methylguanine-DNA methyltransferase in soft tissue sarcomas: association with K-ras mutations. Hum. Pathol. 40: 934-941.

Kim YI, Pogribny IP, Basnakian AG, Miller JW, et al. (1997). Folate deficiency in rats induces DNA strand breaks and hypomethylation within the 553 tumor suppressor gene. Am. J. Clin. Nutr. 65: 46-52.

Kondo Y, Shen L and Issa JP (2003). Critical role of histone methylation in tumor suppressor gene silencing in colorectal cancer. Mol. Cell Biol. 23: 206-215.

Kono S and Chen K (2005). Genetic polymorphisms of methylenetetrahydrofolate reductase and colorectal cancer and adenoma. Cancer Sci. 96: 535-542.

Lee KH, Lee JS, Nam JH, Choi C, et al. (2011). Promoter methylation status of hMLH1, hMSH2, and MGMT genes in colorectal cancer associated with adenoma-carcinoma sequence. Langenbecks Arch. Surg. 396: 1017-1026.

Linnebank M, Semmler A, Moskau S, Smulders Y, et al. (2008). The methylenetetrahydrofolate reductase (MTHFR) variant c.677C $>\mathrm{T}(\mathrm{A} 222 \mathrm{~V})$ influences overall survival of patients with glioblastoma multiforme. Neuro- Oncol. 10 : $548-552$.

Long XD, Ma Y, Zhou YF, Ma AM, et al. (2010). Polymorphism in xeroderma pigmentosum complementation group C codon 939 and aflatoxin B1-related hepatocellular carcinoma in the Guangxi population. Hepatology 52: 1301-1309.

Margison GP and Santibanez-Koref MF (2002). O6-alkylguanine-DNA alkyltransferase: role in carcinogenesis and chemotherapy. Bioessays 24: 255-266.

Nandan NK, Wajid S, Biswas S, Juneja SS, et al. (2008). Allelic variations in 5, 10-methylenetetrahydrofolate reductase gene and susceptibility to cervical cancer in Indian women. Drug Metab. Lett. 2: 18-22.

Pufulete M, Al-Ghnaniem R, Leather AJ, Appleby P, et al. (2003). Folate status, genomic DNA hypomethylation, and risk of colorectal adenoma and cancer: a case control study. Gastroenterology 124: 1240-1248.

Roll JD, Rivenbark AG, Jones WD and Coleman WB (2008). DNMT3b overexpression contributes to a hypermethylator phenotype in human breast cancer cell lines. Mol. Cancer 7: 15 .

Schaich M, Kestel L, Pfirrmann M, Robel K, et al. (2009). A MDR1 (ABCB1) gene single nucleotide polymorphism predicts outcome of temozolomide treatment in glioblastoma patients. Ann. Oncol. 20: 175-181.

Shah N, Lin B, Sibenaller Z, Ryken T, et al. (2011). Comprehensive analysis of MGMT promoter methylation: correlation with MGMT expression and clinical response in GBM. PLoS One 6: e16146.

Steinmann K, Sandner A, Schagdarsurengin U and Dammann RH (2009). Frequent promoter hypermethylation of tumorrelated genes in head and neck squamous cell carcinoma. Oncol. Rep. 22: 1519-1526.

Stern LL, Mason JB, Selhub J and Choi SW (2000). Genomic DNA hypomethylation, a characteristic of most cancers, is present in peripheral leukocytes of individuals who are homozygous for the C677T polymorphism in the methylenetetrahydrofolate reductase gene. Cancer Epidemiol. Biomark. Prev. 9: 849-853.

Tamaru H and Selker EU (2001). A histone H3 methyltransferase controls DNA methylation in Neurospora crassa. Nature 414: 277-283.

Tawbi HA, Villaruz L, Tarhini A, Moschos S, et al. (2011). Inhibition of DNA repair with MGMT pseudosubstrates: phase I study of lomeguatrib in combination with dacarbazine in patients with advanced melanoma and other solid tumours. Br. J. Cancer 105: 773-777.

Theocharis S, Klijanienko J, Giaginis C, Rodriguez J, et al. (2011). Expression of DNA repair proteins, MSH2, MLH1 and MGMT in mobile tongue squamous cell carcinoma: associations with clinicopathological parameters and patients' survival. J. Oral Pathol. Med. 40: 218-226.

Uno M, Oba-Shinjo SM, Camargo AA, Moura RP, et al. (2011). Correlation of MGMT promoter methylation status with gene and protein expression levels in glioblastoma. Clinics 66: 1747-1755.

Virmani AK, Muller C, Rathi A, Zoechbauer-Mueller S, et al. (2001). Aberrant methylation during cervical carcinogenesis. Clin. Cancer Res. 7: 584-589.

Wainfan E and Poirier LA (1992). Methyl groups in carcinogenesis: effects on DNA methylation and gene expression. Cancer Res. 52: 2071s-2077s. 
Wood RD, Mitchell M and Lindahl T (2005). Human DNA repair genes, 2005. Mutat. Res. 577: 275-283.

Yoshino A, Ogino A, Yachi K, Ohta T, et al. (2010). Gene expression profiling predicts response to temozolomide in malignant gliomas. Int. J. Oncol. 36: 1367-1377.

Zhang Y and Chen L (2010). DNA methylation and non-small cell lung cancer. Zhongguo Fei Ai Za Zhi 13: 821-826. 